\title{
PRODUTIVIDADE E COMPOSIÇÃO QUÍMICA DO CAPIM-TIFTON 85 SUBMETIDO A DIFERENTES TAXAS DE APLICAÇÃO DO PERCOLADO DE RESÍDUO SÓLIDO URBANO
}

\author{
ANTONIO T. DE MATOS ${ }^{1}$, DENISE DE F. SILVA², PAOLA A. V. LO MONACO ${ }^{3}$, \\ ODILON G. PEREIRA ${ }^{4}$
}

\begin{abstract}
RESUMO: Este trabalho foi realizado com o objetivo de avaliar o efeito da aplicação de diferentes taxas de percolado de resíduo sólido urbano (RSU) na produtividade e na composição química da parte aérea do capim-Tifton 85 (Cynodon spp). O percolado foi aplicado nas taxas de 0 (testemunha); 250; 500; 750 e $1.000 \mathrm{~kg} \mathrm{ha}^{-1} \mathrm{~d}^{-1}$ de $\mathrm{DBO}_{5}$, durante 8 meses. No tratamento-testemunha, não receptor do percolado, aplicou-se água da rede de abastecimento público, sendo a lâmina de aplicação definida com base na Evapotranspiração de Referência (ETo). O experimento foi analisado no esquema de parcelas subdivididas, tendo nas parcelas cinco concentrações de $\mathrm{DBO}_{5}$, e nas subparcelas, os cortes, no delineamento em blocos casualizados, com quatro repetições. Os dados foram submetidos à análise de regressão e variância. Observou-se aumento na produtividade de matéria seca, nos teores de proteína bruta e nas concentrações de $\mathrm{N}, \mathrm{K}, \mathrm{Na}, \mathrm{Ca}$, $\mathrm{Mg}, \mathrm{Mn}, \mathrm{Cd}, \mathrm{Pb}$ e Fe,na parte aérea do capim,com o aumento nas taxas de aplicação do percolado. As concentrações de N, P e Mn tenderam a decrescer com o número de cortes do capim; as de Cd, $\mathrm{Pb}$ e Fe tenderam à estabilização após o $2^{\circ}$ ou $3^{\circ}$ cortes; e as de $\mathrm{Na}$ tenderam a aumentar após o $3^{\circ}$ corte. As concentrações de $\mathrm{K}, \mathrm{Ca}$ e Mg ficaram instáveis.
\end{abstract}

PALAVRAS-CHAVE: aterro sanitário, chorume, fertirrigação, forrageira.

\section{YIELD AND CHEMICAL COMPOSITION OF TIFTON 85 SUBMITTED TO DIFFERENT RATES OF LANDFILL LEACHATE}

\begin{abstract}
The issue of this study was to evaluate the effect of different rates of landfill leachate (LL) in productivity and chemical composition of Tifton 85 (Cynodon spp). The leachate was applied at rates of 0 (control), 250, 500, 750, 1,000 kg ha-1 $\mathrm{d}^{-1}$ of $\mathrm{BOD}_{5}$, for eight months. In the control treatment, not receiving the leachate, it was applied water from the public supply network being the water depth of application defined based on the Reference Evapotranspiration (ETo). The experiment was analyzed in a split plot, with five plots concentrations of $\mathrm{BOD}_{5}$ and the cuts the subplots in a randomized block design with four replications. The data were subjected to analysis of variance and regression. The dry matter yield, crude protein levels and concentrations of $\mathrm{N}, \mathrm{K}, \mathrm{Na}$, $\mathrm{Ca}, \mathrm{Mg}, \mathrm{Mn}, \mathrm{Cd}, \mathrm{Pb}$ and $\mathrm{Fe}$, in the aerial parts of the Tifton 85, increased with the application rates of the percolate. The concentration of N, P and Mn tended to decrease with the number of grass cuts; for $\mathrm{Cd}, \mathrm{Pb}$ and $\mathrm{Fe}$ tended to stabilize after the $2^{\text {nd }}$ or the $3^{\text {rd }}$ cuts; and the $\mathrm{Na}$ increase after the $3^{\text {rd }}$ cut. The $\mathrm{K}, \mathrm{Ca}$ and $\mathrm{Mg}$ concentrations were unstable.
\end{abstract}

KEYWORDS: sanitary landfill, landfill leachates, fertirrigation, forage.

\footnotetext{
${ }^{1}$ Professor Associado, Departamento de Engenharia Agrícola, Universidade Federal de Viçosa, Viçosa - MG, atmatos@ufv.br.

${ }^{2}$ Professora do Centro Universitário de Sete Lagoas - UNIFEMM, Sete Lagoas - MG, denise.silva@ unifemm.edu.br.

${ }^{3}$ Professora do Instituto Federal de Educação, Ciência e Tecnologia do Espírito Santo, Câmpus Centro Serrano, Santa Maria de Jetibá - ES, paolalomonaco2004@yahoo.com.br.

${ }^{4}$ Professor Associado, Departamento de Zootecnia, Universidade Federal de Viçosa, Viçosa - MG, odilon@ufv.br.

Recebido pelo Conselho Editorial em: 8-7-2011

Aprovado pelo Conselho Editorial em: 7-9-2012
} 


\section{INTRODUÇÃO}

A disposição de resíduos sólidos urbanos (RSU) em aterros sanitários é a forma de gerenciamento predominante em países desenvolvidos, embora alternativas venham sendo propostas atualmente (SLACK et al., 2005). No entanto, somente o aterramento não resolve o problema dos RSU, já que, com a degradação do material orgânico presente no mesmo, há a geração de um líquido escuro, altamente poluidor e de alta carga orgânica e inorgânica, comumente denominado de chorume. Em razão da infiltração de água, geralmente da chuva, no material acondicionado no aterro, há a mistura destas águas com o chorume produzido, gerando o que se denomina "percolado" (GUTIERREZ et al., 2010). A falta de tratamento ou o tratamento inadequado deste percolado pode ocasionar graves impactos ambientais, como a poluição do solo e de águas superficiais e subterrâneas.

O percolado proveniente de aterros sanitários apresenta alta variabilidade composicional, destacando-se a presença de nutrientes importantes para a agricultura, como o nitrogênio, fósforo, potássio, alguns micronutrientes, além de matéria orgânica, atribuindo-lhe elevado potencial para aproveitamento agrícola (MATOS et al., 2008a; SILVA et al., 2011), notadamente no que se refere à fertirrigação em culturas agrícolas; entretanto, o sódio e outros poluentes podem ser fatores limitantes para este aproveitamento.

De acordo com ERTHAL et al. (2010a), a disposição de águas residuárias no sistema solo-planta, quando feita sem critérios agronômicos e ambientais, pode causar problemas de contaminação do solo, das águas superficiais e subterrâneas, e toxicidade às plantas; por outro lado, se bem planejada, esta aplicação pode trazer benefícios, tais como fornecimento de nutrientes e água para as plantas, redução do uso de fertilizantes e de seu potencial poluidor.

O conhecimento sobre os teores de nutrientes e outros componentes das águas residuárias é, fundamentalmente, importante para que se possam propor formas mais adequadas de disposição das mesmas no solo, incluindo o que se refere à definição das taxas de aplicação. Por outro lado, a cultura a ser fertirrigada com a água residuária deve, também, apresentar certas características desejáveis, como um rápido crescimento, grande massa radicular, além de grande capacidade de absorção de nutrientes (MATOS et al., 2008b).

O capim-Tifton tem sido bastante utilizado em diversas formas de tratamento/disposição de águas residuárias como nos sistemas alagados construídos (FIA et al., 2011; MATOS et al., 2008b; 2009; 2010a; 2010b; 2011), na fertirrigação (DRUMMOND et al., 2006; ERTHAL et al., 2010a; 2010b; SILVA et al., 2010; 2011) e por escoamento superficial (QUEIROZ et al., 2004), por reunir tais características. Em trabalho realizado por MATOS et al. (2008b), o capim-Tifton 85, cultivado por quatro meses, apresentou elevadas produtividades acumuladas de matéria seca $\left(15 \mathrm{t} \mathrm{ha}^{-1}\right)$ e proteína bruta $\left(3,7 \mathrm{t} \mathrm{ha}^{-1}\right)$ e relativamente grande capacidade de remover nutrientes $(\mathrm{N}, \mathrm{P}$ e $\mathrm{K})$ e sódio da água residuária de laticínios. Os autores concluíram que este capim é considerado ótima opção para cultivo em sistemas alagados construídos, caso se deseje a produção de forrageiras de grande valor nutricional para alimentação animal. Além da elevada produtividade e capacidade de extração, QUEIROZ et al. (2004) verificaram que o capim-Tifton 85 possui rápida recuperação após o corte, com boa cobertura do solo e o impedimento ao desenvolvimento de espécies invasoras no local.

Apesar do percolado de RSU possuir potencialidade de uso na agricultura, existe pouca informação referente a seus efeitos no sistema solo-planta. Portanto, torna-se evidente a importância de estudos concernentes aos efeitos, decorrentes da disposição do percolado de RSU, no ambiente, nas plantas e no solo, na tentativa de viabilizar tecnologias alternativas para seu tratamento/disposição final. Com base no exposto, este trabalho foi realizado com o objetivo de avaliar o efeito de diferentes taxas de aplicação do percolado de resíduo sólido urbano na produtividade e na composição química da parte aérea do capim-Tifton 85 (Cynodon spp). 


\section{MATERIAL E MÉTODOS}

O experimento foi conduzido de 07/10/2006 a 01/06/2007 na Área Experimental de Tratamento de Resíduos Urbanos (coordenadas geográficas de $20^{\circ} 45^{\prime}$ de latitude sul e $42^{\circ} 51^{\prime}$ de longitude oeste e altitude de $650 \mathrm{~m}$ ) do Departamento de Engenharia Agrícola, na Universidade Federal de Viçosa, Viçosa - MG.

Para o desenvolvimento desta pesquisa, um reservatório de $5.000 \mathrm{~L}$ foi preenchido com RSU novo (recém-coletado), visando-se à produção de percolado. Para preenchimento do reservatório de produção de percolado, utilizou-se o RSU contido em dois caminhões de coleta efetuada na cidade de Viçosa-MG. A composição gravimétrica do RSU foi feita por quarteamento, despejando-se os resíduos sobre uma lona plástica e formando uma única pilha. $\mathrm{O}$ material foi espalhado e homogeneizado e, em seguida, quarteado. O componente de maior percentual no RSU foi a matéria orgânica (56,4\%), seguida de papel/papelão $(6,3 \%)$ e plástico fino $(7,3 \%)$, constituintes que representaram $70,0 \%$ da massa total. Como o período era de baixa pluviosidade, aplicou-se, com o auxílio de um regador, água da rede de abastecimento da UFV sobre o RSU, para agilizar o início na produção de percolado. Assim, o percolado começou a ser aplicado nas parcelas experimentais após 21 dias de armazenamento do RSU.

O percolado produzido neste reservatório era conduzido para um reservatório de $500 \mathrm{~L}$, do qual era, então, recalcado para outro reservatório de igual volume, localizado próximo à área experimental em que era feita a aplicação do percolado (Figura 1). O solo da área experimental, segundo critérios estabelecidos pela Sociedade Brasileira de Ciência do Solo - SBCS, foi classificado como Cambissolo Háplico Tb distrófico latossólico.

Em razão da grande declividade na área de cultivo do capim, foram construídos quatro patamares, em curva de nível, e delimitadas 20 parcelas de $4 \mathrm{~m}^{2}$ ( $\left.2 \times 2 \mathrm{~m}\right)$ cada uma, além de instaladas cinco parcelas em cada patamar.

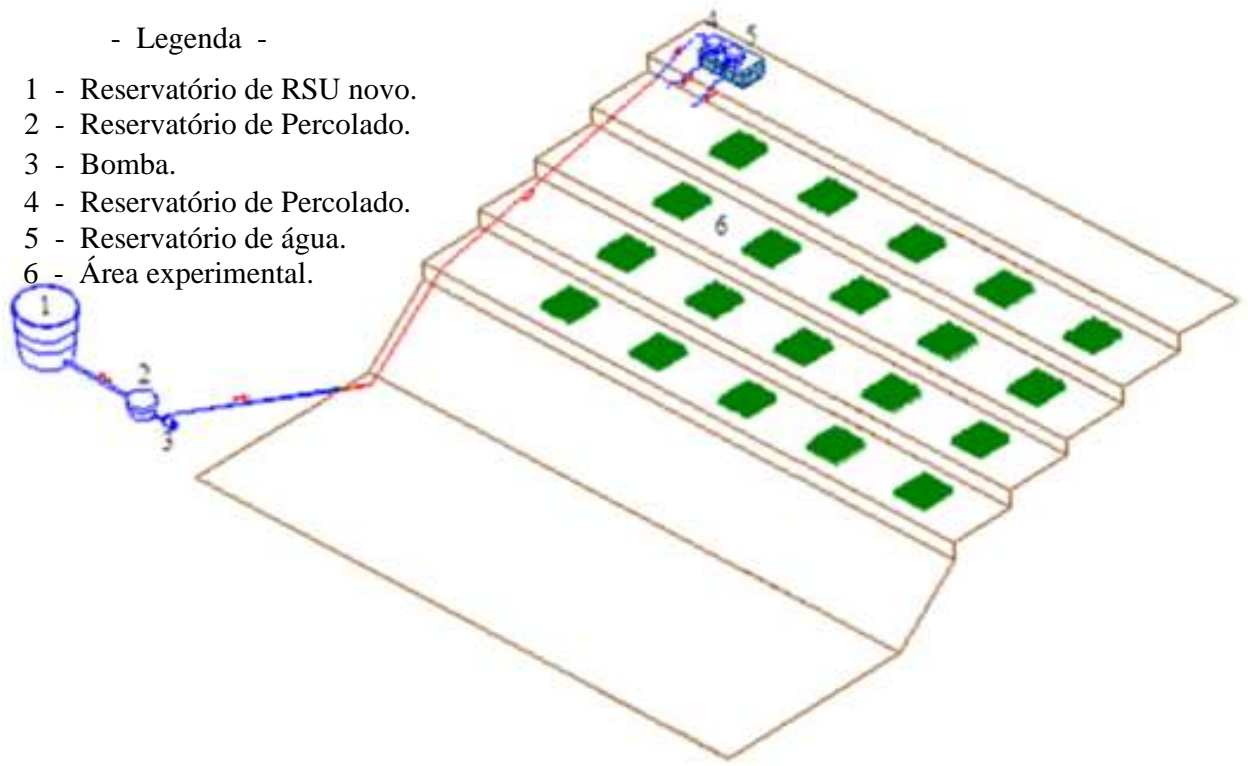

FIGURA 1. Esquema de condução e distribuição do percolado nos reservatórios. Driving scheme and distribution of leachate in the reservoirs.

Durante o período experimental, foram realizadas seis coletas de amostra do percolado do segundo reservatório, o que foi feito aproximadamente a cada 30 dias. O percolado era agitado antes das amostragens e coletado em vários pontos do reservatório, e posteriormente misturado, gerando amostras compostas, estando as principais características químicas do líquido apresentadas na Tabela 1. 
TABELA 1. Faixa de variação da composição química do percolado de RSU (seis amostras) coletado mensalmente durante o período experimental. Variation range of the chemical composition of RSU leachate (six samples) collected monthly during the experimental period.

\begin{tabular}{|c|c|c|c|c|}
\hline Variáveis & Unidade & \multicolumn{3}{|c|}{ Faixa de variação $^{* * *}$} \\
\hline $\mathrm{pH}$ & - & 5,68 & - & 7,70 \\
\hline $\mathrm{CE}$ & $\mathrm{mS} \mathrm{cm}^{-1}$ & 12,31 & - & 19,37 \\
\hline DBO & $\mathrm{mg} \mathrm{L}^{-1}$ & 5.363 & - & 31.598 \\
\hline DQO & $\mathrm{mg} \mathrm{L}^{-1}$ & 10.726 & - & 63.196 \\
\hline $\mathrm{N}$ & $\mathrm{mg} \mathrm{L}^{-1}$ & 124,5 & - & $1.576,0$ \\
\hline$P$ & $\mathrm{mg} \mathrm{L}^{-1}$ & 41,3 & - & 108,5 \\
\hline $\mathrm{K}^{+}$ & $\mathrm{mg} \mathrm{L}^{-1}$ & 106,3 & - & $3.663,5$ \\
\hline $\mathrm{Na}^{+}$ & $\mathrm{mg} \mathrm{L}^{-1}$ & 99,2 & - & $3.588,8$ \\
\hline $\mathrm{Ca}^{2+}$ & $\mathrm{mg} \mathrm{L}^{-1}$ & 78,4 & - & $1.267,3$ \\
\hline $\mathrm{Mg}^{2+}$ & $\mathrm{mg} \mathrm{L}^{-1}$ & 69,5 & - & $9.541,7$ \\
\hline RAS $^{*}$ & $\left(\mathrm{mmol}_{\mathrm{c}} \mathrm{L}^{-1}\right)^{0,5}$ & 2,8 & - & 10,4 \\
\hline $\mathrm{Zn}$ & $\operatorname{mg~L} L^{-1}$ & 0,0 & - & 8,3 \\
\hline $\mathrm{Fe}$ & $\mathrm{mg} \mathrm{L}^{-1}$ & 83,4 & - & 981,3 \\
\hline $\mathrm{Cu}$ & $\mathrm{mg} \mathrm{L}^{-1}$ & 0,0 & - & 16,3 \\
\hline Mn & $\mathrm{mg} \mathrm{L}^{-1}$ & 2,6 & - & 33,1 \\
\hline $\mathrm{Cr}$ & $\mathrm{mg} \mathrm{L}^{-1}$ & 0,0 & - & 2,0 \\
\hline $\mathrm{Ni}$ & $\mathrm{mg} \mathrm{L}^{-1}$ & 0,0 & - & 1,6 \\
\hline $\mathrm{N}-\mathrm{NH}_{4}{ }^{+}$ & $\mathrm{mg} \mathrm{L}^{-1}$ & 71,7 & - & 286,7 \\
\hline $\mathrm{N}-\mathrm{NO}_{3}^{-}$ & $\mathrm{mg} \mathrm{L}^{-1}$ & 3,2 & - & 8,3 \\
\hline
\end{tabular}

"RAS - razão de adsorção de sódio.

Verificou-se relativamente grande variação nas características químicas do percolado de RSU ao longo do tempo de experimentação, o que está associado ao fato de que, inicialmente, o RSU é capaz de disponibilizar maior quantidade de material particulado e sólidos solúveis no percolado.

O plantio do capim-Tifton 85 foi realizado utilizando-se de mudas, obtidas no Setor de Agrostologia do Departamento de Zootecnia da Universidade Federal de Viçosa, em sulcos de aproximadamente $0,15 \mathrm{~m}$ de profundidade, espaçados em $0,30 \mathrm{~m}$, com distanciamento de $0,20 \mathrm{~m}$ entre plantas.

Durante a fase de estabelecimento das plantas, o capim foi irrigado com água da rede de abastecimento da UFV. O percolado do RSU e a água da rede de abastecimento foram coletados, separadamente, em reservatórios de $500 \mathrm{~L}$, sendo aplicados nas parcelas experimentais com auxílio de regadores.

O percolado de RSU foi aplicado ao solo utilizando-se de um regador e aplicando-se as taxas de 250; 500; 750 e $1.000 \mathrm{~kg} \mathrm{ha}^{-1} \mathrm{~d}^{-1}$ de DBO, sendo que nessas parcelas não foi aplicada água da rede de abastecimento. Como tratamento-testemunha, utilizado para efeito comparativo com os tratamentos em que foi aplicado o percolado de RSU, o capim foi irrigado apenas com água da rede de abastecimento, sendo a lâmina de aplicação definida com base na Evapotranspiração de Referência (ETo), que foi estimada por meio do método de Penman-Monteith (ALLEN et al., 1998). Para estimativa da lâmina evapotranspirada, utilizou-se o programa IRRIPLUS (MANTOVANI et al. 2009).

Durante o período de aplicação do percolado nas parcelas cultivadas com o capim-Tifton, foram efetuados cinco cortes na parte aérea das plantas, sempre que o capim atingia $0,40 \mathrm{~m}$, já que, a partir dessa altura, começa a tombar. As idades dos cortes corresponderam a 30; 61; 97; 143 e 209 dias após o início da aplicação do percolado. 
$\mathrm{O}$ corte do capim foi feito a $0,10 \mathrm{~m}$ de altura em relação à superfície do solo, em área útil de $1 \mathrm{~m}^{2}$, eliminando-se a bordadura $(0,5 \mathrm{~m}$ nas laterais e nas extremidades), com auxílio de cutelo. Após cada corte, a biomassa foi recolhida e pesada. Em seguida, as amostras de cada parcela foram levadas ao Laboratório de Forragicultura do Departamento de Zootecnia da UFV, para realização da pré-secagem em estufa com circulação forçada de ar, sob temperatura de $65{ }^{\circ} \mathrm{C}$, durante um período de 72 horas. Posteriormente, as amostras foram pesadas em balança de precisão e moídas em moinho tipo "Willey", com peneiras de 30 mesh de malha; essas amostras foram guardadas em vidros, com tampa, para posteriores análises de nutrientes e metais pesados. Parte das amostras foram secadas em estufa a $105^{\circ} \mathrm{C}$, para quantificação da matéria seca produzida.

Nas amostras moídas do capim, foram quantificadas as concentrações de N, P, K, Na, Ca e $\mathrm{Mg}$, segundo metodologias descritas por SILVA \& QUEIROZ (2002), e os metais pesados Fe, Mn, $\mathrm{Cu}, \mathrm{Pb}, \mathrm{Zn}, \mathrm{Cd}$ e $\mathrm{Ni}$, foram obtidos por espectrometria de absorção atômica (APHA, 2005). O conteúdo de proteína bruta foi obtido, multiplicando-se o teor de nitrogênio por 6,25.

Adotou-se o delineamento experimental em blocos casualizados, com cinco tratamentos e quatro repetições.As concentrações de nutrientes nas plantas foram analisadas no esquema de parcelas subdivididas, tendo nas parcelas cinco concentrações de DBO e nas subparcelas os cortes, no delineamento em blocos casualizados, com quatro repetições. Os dados foram submetidos à análise de variância, teste de média e análise de regressão, utilizando-se do programa SAEG. Na análise de variância, empregou-se o teste $\mathrm{F}$, a $5 \%$ de probabilidade. As médias foram comparadas, utilizando-se do teste de Tukey, a 5\% de probabilidade. Os modelos de regressão foram escolhidos com base na significância dos coeficientes de regressão, utilizando-se do teste t, num nível de até $15 \%$ de probabilidade, no coeficiente de determinação $\left(\mathrm{R}^{2}\right)$ e no fenômeno em estudo. Independentemente de a interação ser ou não significativa, optou-se pelo desdobramento da mesma devido ao interesse em estudo.

\section{RESULTADOS E DISCUSSÃO}

$\mathrm{Na}$ análise quantitativa, estão apresentadas, na Tabela 2, as equações de regressão ajustadas para a estimativa da produtividade de matéria seca e concentração de proteína bruta, $\mathrm{P}, \mathrm{K}, \mathrm{Ca}, \mathrm{Mg}$, $\mathrm{Na}, \mathrm{Mn}, \mathrm{Cd}, \mathrm{Pb}$ e $\mathrm{Fe}$, na parte aérea do capim-Tifton 85, em função da taxa de aplicação de percolado de RSU. Como análise qualitativa, na Tabela 3, está apresentado o teste de médias para as mesmas variáveis, considerando-se o efeito dos cortes 1 (30 dias), 2 (61 dias), 3 (97 dias), 4 (143 dias) e 5 (209 dias) na parte aérea do capim, para cada taxa de aplicação de percolado de RSU.

Com base nos ajustes obtidos de equações lineares e quadráticas, verifica-se que, à exceção de MS até o segundo corte e à concentração de Fe, no terceiro corte, houve aumento das demais variáveis na parte aérea do capim, com o aumento na taxa de aplicação de percolado de RSU. Isso indicou efeito positivo da aplicação do percolado na nutrição do capim-Tifton 85 . 
TABELA 2. Produtividade de matéria seca (MS), em kg ha ${ }^{-1}$; concentração de proteína bruta (PB), P, K, $\mathrm{Ca}, \mathrm{Mg}$ e $\mathrm{Na}$, em dag $\mathrm{kg}^{-1}$; e de $\mathrm{Mn}, \mathrm{Cd}, \mathrm{Pb}, \mathrm{Fe}$, em $\mathrm{mg} \mathrm{kg}^{-1}$, em função da taxa de aplicação de percolado de RSU, nos cinco cortes do capim-Tifton 85. Yield of dry matter (MS) in $\mathrm{kg} \mathrm{ha}^{-1}$; crude protein (PB), $\mathrm{P}, \mathrm{K}, \mathrm{Ca}, \mathrm{Mg}$ and $\mathrm{Na}$ in dag $\mathrm{kg}^{-1}$, and $\mathrm{Mn}, \mathrm{Cd}$, $\mathrm{Pb}, \mathrm{Fe}$, in $\mathrm{mg} \mathrm{kg}^{-1}$, according to the application rate of MSW leachate in the five cuts of the Tifton 85 .

\begin{tabular}{|c|c|c|c|}
\hline Variável & Corte & Equação ajustada & $\mathrm{R}^{2}$ \\
\hline \multirow{5}{*}{ MS } & 1 & $\overline{\mathrm{Y}}=2317,60$ & - \\
\hline & 2 & $\bar{Y}=2015,07$ & - \\
\hline & 3 & $\hat{\mathrm{Y}}=1297,88+0,28 * \mathrm{~T}-0,0018 * \mathrm{~T}^{2}$ & 0,9787 \\
\hline & 4 & $\hat{\mathrm{Y}}=515,55+0,75^{*} \mathrm{~T}$ & 0,8282 \\
\hline & 5 & $\hat{\mathrm{Y}}=1520,09+0,75 * \mathrm{~T}$ & 0,8240 \\
\hline \multirow{5}{*}{ PB } & 1 & $\hat{\mathrm{Y}}=22,17+0,017 * \mathrm{~T}-0,000011 * \mathrm{~T}^{2}$ & 0,9056 \\
\hline & 2 & $\hat{\mathrm{Y}}=18,42+0,0056^{*} \mathrm{~T}$ & 0,8339 \\
\hline & 3 & $\hat{\mathrm{Y}}=13,17+0,0055^{* * * \mathrm{~T}}$ & 0,9903 \\
\hline & 4 & $\hat{\mathrm{Y}}=12,12+0,0044 * * \mathrm{~T}$ & 0,8959 \\
\hline & 5 & $\hat{\mathrm{Y}}=10,25+0,0050 * * \mathrm{~T}$ & 0,9514 \\
\hline \multirow{5}{*}{$\mathrm{P}$} & 1 & $\hat{\mathrm{Y}}=0,51+0,00011 * * \mathrm{~T}$ & 0,8888 \\
\hline & 2 & $\hat{\mathrm{Y}}=0,31+0,00028 * * \mathrm{~T}$ & 0,9408 \\
\hline & 3 & $\hat{\mathrm{Y}}=0,39+0,00018 * \mathrm{~T}$ & 0,8599 \\
\hline & 4 & $\hat{\mathrm{Y}}=0,29+0,00028^{*} \mathrm{~T}-0,00000015^{\mathrm{o}} \mathrm{T}^{2}$ & 0,9540 \\
\hline & 5 & $\hat{\mathrm{Y}}=0,30+0,00020^{\circ 0} \mathrm{~T}-0,00000012^{\circ 0} \mathrm{~T}^{2}$ & 0,8775 \\
\hline \multirow{5}{*}{$\mathrm{K}$} & 1 & $\hat{\mathrm{Y}}=1,61+0,0017 * * \mathrm{~T}$ & 0,8738 \\
\hline & 2 & $\hat{\mathrm{Y}}=1,14+0,0011 * * \mathrm{~T}$ & 0,9561 \\
\hline & 3 & $\hat{\mathrm{Y}}=1,01+0,0018^{* *} \mathrm{~T}$ & 0,9421 \\
\hline & 4 & $\hat{\mathrm{Y}}=1,181+0,0016^{*} \mathrm{~T}$ & 0,9636 \\
\hline & 5 & $\hat{\mathrm{Y}}=1,03+0,0024 * * \mathrm{~T}-0,0000016^{*} \mathrm{~T}^{2}$ & 0,9982 \\
\hline \multirow{5}{*}{$\mathrm{Ca}$} & 1 & $\hat{\mathrm{Y}}=0,49+0,00072^{*} \mathrm{~T}-0,00000046^{\mathrm{o}} \mathrm{T}^{2}$ & 0,9404 \\
\hline & 2 & $\hat{\mathrm{Y}}=0,41+0,00060 * * \mathrm{~T}-0,00000038 * \mathrm{~T}^{2}$ & 0,9874 \\
\hline & 3 & $\hat{\mathrm{Y}}=0,48+0,00011 * \mathrm{~T}$ & 0,9339 \\
\hline & 4 & $\hat{\mathrm{Y}}=0,40+0,00034 * \mathrm{~T}-0,00000019^{\circ} \mathrm{T}^{2}$ & 0,9749 \\
\hline & 5 & $\hat{\mathrm{Y}}=0,48+0,00014 * \mathrm{~T}$ & 0,9148 \\
\hline \multirow{5}{*}{$\mathrm{Mg}$} & 1 & $\hat{\mathrm{Y}}=0,26+0,000062 * \mathrm{~T}$ & 0,7853 \\
\hline & 2 & $\hat{\mathrm{Y}}=0,19+0,00010 * * \mathrm{~T}$ & 0,9498 \\
\hline & 3 & $\hat{\mathrm{Y}}=0,18+0,000095^{*} \mathrm{~T}$ & 0,8085 \\
\hline & 4 & $\hat{\mathrm{Y}}=0,18+0,00030^{\circ} \mathrm{T}-0,00000022^{\mathrm{oo}} \mathrm{T}^{2}$ & 0,8329 \\
\hline & 5 & $\hat{\mathrm{Y}}=0,14+0,00026^{\circ} \mathrm{T}-0,00000015^{\mathrm{oo}} \mathrm{T}^{2}$ & 0,8792 \\
\hline \multirow{5}{*}{$\mathrm{Na}$} & 1 & $\hat{\mathrm{Y}}=0,041+0,00021 * * \mathrm{~T}$ & 0,9488 \\
\hline & 2 & $\hat{\mathrm{Y}}=0,024+0,000080 * * \mathrm{~T}$ & 0,9491 \\
\hline & 3 & $\hat{\mathrm{Y}}=0,018+0,000053^{*} \mathrm{~T}$ & 0,9190 \\
\hline & 4 & $\hat{\mathrm{Y}}=0,016+0,00027 * \mathrm{~T}-0,00000015^{\circ} \mathrm{T}^{2}$ & 0,9582 \\
\hline & 5 & $\hat{\mathrm{Y}}=0,021+0,00033^{*} \mathrm{~T}-0,00000019^{\circ} \mathrm{T}^{2}$ & 0,9624 \\
\hline \multirow{5}{*}{$\mathrm{Mn}$} & 1 & $\hat{\mathrm{Y}}=76,84+0,17 * * \mathrm{~T}$ & 0,8762 \\
\hline & 2 & $\hat{\mathrm{Y}}=87,28+0,14 * * \mathrm{~T}$ & 0,8765 \\
\hline & 3 & $\hat{\mathrm{Y}}=93,94+0,11 * * \mathrm{~T}$ & 0,9518 \\
\hline & 4 & $\hat{\mathrm{Y}}=94,07+0,035^{* *} \mathrm{~T}$ & 0,9537 \\
\hline & 5 & $\hat{\mathrm{Y}}=89,61+0,043 * * \mathrm{~T}$ & 0,8799 \\
\hline \multirow{5}{*}{$\mathrm{Cd}$} & 1 & $\hat{\mathrm{Y}}=2,60+0,00083 * \mathrm{~T}$ & 0,6572 \\
\hline & 2 & $\hat{\mathrm{Y}}=2,42+0,00069 * \mathrm{~T}$ & 0,8260 \\
\hline & 3 & $\hat{\mathrm{Y}}=2,15+0,00070^{* * \mathrm{~T}}$ & 0,9629 \\
\hline & 4 & $\hat{\mathrm{Y}}=2,16+0,0014^{*} \mathrm{~T}-0,00000079^{\circ} \mathrm{T}^{2}$ & 0,9628 \\
\hline & 5 & $\hat{\mathrm{Y}}=2,13+0,0014 * \mathrm{~T}-0,00000088^{\circ} \mathrm{T}^{2}$ & 0,9439 \\
\hline \multirow{5}{*}{$\mathrm{Pb}$} & 1 & $\hat{\mathrm{Y}}=20,81+0,0051 * * * \mathrm{~T}$ & 0,9783 \\
\hline & 2 & $\hat{\mathrm{Y}}=20,49+0,0044 * * \mathrm{~T}$ & 0,9633 \\
\hline & 3 & $\hat{\mathrm{Y}}=19,50+0,0030 * * \mathrm{~T}$ & 0,9363 \\
\hline & 4 & $\hat{\mathrm{Y}}=19,41+0,0028 * * \mathrm{~T}$ & 0,9573 \\
\hline & 5 & $\hat{\mathrm{Y}}=19,26+0,0031 * * * \mathrm{~T}$ & 0,9929 \\
\hline \multirow{5}{*}{$\mathrm{Fe}$} & 1 & $\hat{\mathrm{Y}}=378,10+0,87 * \mathrm{~T}$ & 0,8100 \\
\hline & 2 & $\hat{\mathrm{Y}}=387,04+0,31 * * \mathrm{~T}$ & 0,9417 \\
\hline & 3 & $\bar{Y}=399,09$ & - \\
\hline & 4 & $\hat{\mathrm{Y}}=294,18+0,31 * * \mathrm{~T}$ & 0,9222 \\
\hline & 5 & $\hat{\mathrm{Y}}=251,16+0,41 * * * \mathrm{~T}$ & 0,9834 \\
\hline
\end{tabular}

***, **, $*,{ }^{\mathrm{o}} \mathrm{e}{ }^{\mathrm{oo}}$ significativo a $0,1 \%, 1 \%, 5 \%, 10 \%$ e $15 \%$ de probabilidade, respectivamente, pelo teste t. 
TABELA 3. Produtividade média da matéria seca (MS), conteúdos médios da proteína bruta (PB) e concentrações médias de macro e micronutrientes no capim-Tifton 85, submetido a diferentes taxas de aplicação e diferentes cortes, durante o período de cultivo de 209 dias. Average productivity of dry matter (MS), average content of crude protein (PB) and concentrations of macro and micronutrients in Tifton 85 , subjected to different application rates and different cuts, during the cultivation period of 209 days.

\begin{tabular}{|c|c|c|c|c|c|c|}
\hline \multirow{6}{*}{$\begin{array}{c}\mathrm{MS} \\
\left(\mathrm{kg} \mathrm{ha}^{-1}\right)\end{array}$} & Corte & T0 & T1 & T2 & T3 & T4 \\
\hline & 1 & $2.553,2 \mathrm{~A}$ & $2.446,3 \mathrm{~A}$ & $2.266,2 \mathrm{~A}$ & $2.581,1 \mathrm{~A}$ & $2.324,0 \mathrm{~A}$ \\
\hline & 2 & $1.673,5 \mathrm{~B}$ & $2.160,5 \mathrm{~B}$ & $1.841,7 \mathrm{~B}$ & $2.327,6 \mathrm{~B}$ & $2.076,0 \mathrm{~B}$ \\
\hline & 3 & $1.280,3 \mathrm{C}$ & $1.962,4 \mathrm{C}$ & $2.169,5 \mathrm{~A}$ & $2.477,4 \mathrm{AB}$ & $1.741,2 \mathrm{C}$ \\
\hline & 4 & $501,2 \mathrm{D}$ & $745,2 \mathrm{D}$ & $750,4 \mathrm{C}$ & $1.292,3 \mathrm{C}$ & $1.166,8 \mathrm{D}$ \\
\hline & 5 & $504,8 \mathrm{D}$ & $748,0 \mathrm{D}$ & $757,9 \mathrm{C}$ & $1.290, \mathrm{C}$ & $1.167,7 \mathrm{D}$ \\
\hline \multirow{5}{*}{$\begin{array}{c}\mathrm{PB} \\
\left(\text { dag kg }^{-1}\right)\end{array}$} & 1 & $21,8 \mathrm{~A}$ & $26,3 \mathrm{~A}$ & $28,4 \mathrm{~A}$ & $27,2 \mathrm{~A}$ & $28,4 \mathrm{~A}$ \\
\hline & 2 & $17,2 \mathrm{~B}$ & $21,0 \mathrm{~B}$ & $22,1 \mathrm{~B}$ & $22,2 \mathrm{~B}$ & $23,6 \mathrm{~B}$ \\
\hline & 3 & $13,3 \mathrm{C}$ & $14,5 \mathrm{C}$ & $16,0 \mathrm{C}$ & $17,0 \mathrm{C}$ & $19,0 \mathrm{C}$ \\
\hline & 4 & $11,7 \mathrm{CD}$ & $13,5 \mathrm{CD}$ & $15,1 \mathrm{CD}$ & $14,7 \mathrm{CD}$ & $16,5 \mathrm{CD}$ \\
\hline & 5 & $10,2 \mathrm{D}$ & $11,1 \mathrm{D}$ & $13,5 \mathrm{D}$ & $14,2 \mathrm{D}$ & $14,9 \mathrm{D}$ \\
\hline \multirow{5}{*}{$\begin{array}{c}\mathrm{P} \\
\left(\operatorname{dag~kg}{ }^{-1}\right)\end{array}$} & 1 & $0,53 \mathrm{~A}$ & $0,54 \mathrm{~A}$ & $0,55 \mathrm{~A}$ & $0,58 \mathrm{~A}$ & $0,64 \mathrm{~A}$ \\
\hline & 2 & $0,28 \mathrm{C}$ & $0,39 \mathrm{C}$ & $0,51 \mathrm{AB}$ & $0,53 \mathrm{AB}$ & $0,57 \mathrm{~B}$ \\
\hline & 3 & $0,36 \mathrm{~B}$ & $0,45 \mathrm{~B}$ & $0,48 \mathrm{~B}$ & $0,53 \mathrm{~B}$ & $0,54 \mathrm{~B}$ \\
\hline & 4 & $0,28 \mathrm{C}$ & $0,35 \mathrm{C}$ & $0,39 \mathrm{C}$ & $0,39 \mathrm{C}$ & $0,42 \mathrm{C}$ \\
\hline & 5 & $0,29 \mathrm{C}$ & $0,35 \mathrm{C}$ & $0,37 \mathrm{C}$ & $0,36 \mathrm{C}$ & $0,38 \mathrm{C}$ \\
\hline \multirow{5}{*}{$\frac{\mathrm{K}}{\left(\operatorname{dag~kg}^{-1}\right)}$} & 1 & $1,73 \mathrm{~A}$ & $2,10 \mathrm{~A}$ & $2,30 \mathrm{~A}$ & $2,56 \mathrm{~A}$ & $3,66 \mathrm{~A}$ \\
\hline & 2 & $1,14 \mathrm{~B}$ & $1,51 \mathrm{~B}$ & $1,63 \mathrm{C}$ & $1,87 \mathrm{~B}$ & $2,37 \mathrm{C}$ \\
\hline & 3 & $1,15 \mathrm{~B}$ & $1,43 \mathrm{~B}$ & $1,62 \mathrm{C}$ & $2,47 \mathrm{~A}$ & $2,88 \mathrm{~B}$ \\
\hline & 4 & $1,09 \mathrm{~B}$ & $1,65 \mathrm{~B}$ & $1,99 \mathrm{~B}$ & $2,54 \mathrm{~A}$ & $2,63 \mathrm{BC}$ \\
\hline & 5 & $1,05 \mathrm{~B}$ & $1,47 \mathrm{~B}$ & $1,82 \mathrm{~B}$ & $1,96 \mathrm{~B}$ & $1,80 \mathrm{D}$ \\
\hline \multirow{5}{*}{$\begin{array}{c}\mathrm{Ca} \\
\left(\operatorname{dag~kg}{ }^{-1}\right)\end{array}$} & 1 & $0,48 \mathrm{~A}$ & $0,68 \mathrm{~A}$ & $0,75 \mathrm{~A}$ & $0,74 \mathrm{~A}$ & $0,78 \mathrm{~A}$ \\
\hline & 2 & $0,42 \mathrm{BC}$ & $0,52 \mathrm{BC}$ & $0,62 \mathrm{~B}$ & $0,65 \mathrm{~B}$ & 0,63 B \\
\hline & 3 & $0,47 \mathrm{~A}$ & $0,52 \mathrm{~B}$ & $0,53 \mathrm{C}$ & $0,56 \mathrm{C}$ & $0,59 \mathrm{BC}$ \\
\hline & 4 & $0,40 \mathrm{C}$ & $0,48 \mathrm{C}$ & $0,54 \mathrm{C}$ & $0,54 \mathrm{C}$ & $0,56 \mathrm{C}$ \\
\hline & 5 & $0,46 \mathrm{AB}$ & $0,51 \mathrm{BC}$ & $0,57 \mathrm{C}$ & $0,58 \mathrm{C}$ & $0,60 \mathrm{BC}$ \\
\hline \multirow{5}{*}{$\begin{array}{c}\mathrm{Mg} \\
\left(\operatorname{dag~kg}^{-1}\right)\end{array}$} & 1 & $0,24 \mathrm{~A}$ & $0,29 \mathrm{~A}$ & $0,30 \mathrm{~A}$ & $0,30 \mathrm{~A}$ & $0,32 \mathrm{~A}$ \\
\hline & 2 & $0,18 \mathrm{~B}$ & $0,23 \mathrm{C}$ & $0,25 \mathrm{C}$ & $0,27 \mathrm{~B}$ & $0,29 \mathrm{~B}$ \\
\hline & 3 & $0,16 \mathrm{C}$ & $0,23 \mathrm{C}$ & $0,24 \mathrm{CD}$ & $0,26 \mathrm{~B}$ & $0,26 \mathrm{C}$ \\
\hline & 4 & $0,16 \mathrm{C}$ & $0,26 \mathrm{~B}$ & $0,27 \mathrm{~B}$ & $0,26 \mathrm{~B}$ & $0,27 \mathrm{BC}$ \\
\hline & 5 & $0,13 \mathrm{D}$ & $0,22 \mathrm{C}$ & $0,22 \mathrm{D}$ & $0,24 \mathrm{C}$ & $0,26 \mathrm{C}$ \\
\hline \multirow{5}{*}{$\begin{array}{c}\mathrm{Na} \\
\left(\operatorname{dag~kg}^{-1}\right)\end{array}$} & 1 & $0,02 \mathrm{~A}$ & $0,12 \mathrm{~A}$ & $0,16 \mathrm{~A}$ & $0,18 \mathrm{~A}$ & $0,25 \mathrm{~A}$ \\
\hline & 2 & $0,02 \mathrm{~A}$ & $0,05 \mathrm{C}$ & $0,07 \mathrm{C}$ & $0,08 \mathrm{D}$ & $0,10 \mathrm{D}$ \\
\hline & 3 & $0,01 \mathrm{~A}$ & $0,04 \mathrm{C}$ & $0,05 \mathrm{D}$ & $0,06 \mathrm{D}$ & $0,06 \mathrm{E}$ \\
\hline & 4 & $0,01 \mathrm{~A}$ & $0,09 \mathrm{~B}$ & $0,11 \mathrm{~B}$ & $0,12 \mathrm{C}$ & $0,14 \mathrm{C}$ \\
\hline & 5 & $0,01 \mathrm{~A}$ & $0,11 \mathrm{AB}$ & $0,14 \mathrm{AB}$ & $0,15 \mathrm{~B}$ & $0,17 \mathrm{~B}$ \\
\hline \multirow{5}{*}{$\begin{array}{c}\mathrm{Mn} \\
\left(\mathrm{mg} \mathrm{kg}^{-1}\right)\end{array}$} & 1 & $97,4 \mathrm{AB}$ & $110,8 \mathrm{AB}$ & $146,7 \mathrm{~A}$ & $174,0 \mathrm{~A}$ & $276,2 \mathrm{~A}$ \\
\hline & 2 & $105,1 \mathrm{~A}$ & $118,7 \mathrm{~A}$ & $139,6 \mathrm{~A}$ & $173,8 \mathrm{~A}$ & $255,8 \mathrm{~B}$ \\
\hline & 3 & $104,6 \mathrm{~A}$ & $116,3 \mathrm{~A}$ & $140,6 \mathrm{~A}$ & $171,7 \mathrm{~A}$ & $217,2 \mathrm{C}$ \\
\hline & 4 & $90,4 \mathrm{BC}$ & $105,5 \mathrm{~B}$ & 114,9 B & 119,7 B & $126,9 \mathrm{D}$ \\
\hline & 5 & $81,9 \mathrm{C}$ & $107,1 \mathrm{~B}$ & $116,8 \mathrm{~B}$ & $120,2 \mathrm{~B}$ & $128,7 \mathrm{D}$ \\
\hline \multirow{5}{*}{$\begin{array}{c}\mathrm{Cd} \\
\left(\mathrm{mg} \mathrm{kg}^{-1}\right)\end{array}$} & 1 & $2,76 \mathrm{~A}$ & $2,43 \mathrm{~A}$ & $3,25 \mathrm{~A}$ & $3,25 \mathrm{~A}$ & $3,40 \mathrm{~A}$ \\
\hline & 2 & $2,26 \mathrm{AB}$ & $2,71 \mathrm{~A}$ & $2,87 \mathrm{AB}$ & $2,99 \mathrm{AB}$ & $2,99 \mathrm{AB}$ \\
\hline & 3 & $2,14 \mathrm{~B}$ & $2,26 \mathrm{~A}$ & $2,58 \mathrm{~B}$ & $2,68 \mathrm{~B}$ & $2,81 \mathrm{~B}$ \\
\hline & 4 & $2,12 \mathrm{~B}$ & $2,52 \mathrm{~A}$ & $2,62 \mathrm{~B}$ & $2,70 \mathrm{~B}$ & $2,76 \mathrm{~B}$ \\
\hline & 5 & $2,09 \mathrm{~B}$ & $2,50 \mathrm{~A}$ & $2,56 \mathrm{~B}$ & $2,62 \mathrm{~B}$ & $2,64 \mathrm{~B}$ \\
\hline \multirow{5}{*}{$\begin{array}{c}\mathrm{Pb} \\
\left(\mathrm{mg} \mathrm{kg}^{-1}\right)\end{array}$} & 1 & $20,9 \mathrm{~A}$ & $21,8 \mathrm{~A}$ & $23,7 \mathrm{~A}$ & $24,3 \mathrm{~A}$ & $26,1 \mathrm{~A}$ \\
\hline & 2 & $20,7 \mathrm{~A}$ & $21,6 \mathrm{~A}$ & $22,1 \mathrm{~B}$ & $24,1 \mathrm{~A}$ & $25,0 \mathrm{~A}$ \\
\hline & 3 & $19,2 \mathrm{~B}$ & $20,3 \mathrm{~B}$ & $21,5 \mathrm{BC}$ & $21,7 \mathrm{~B}$ & $22,3 \mathrm{~B}$ \\
\hline & 4 & $19,2 \mathrm{~B}$ & $20,4 \mathrm{~B}$ & $20,9 \mathrm{BC}$ & $21,2 \mathrm{~B}$ & $22,3 \mathrm{~B}$ \\
\hline & 5 & $19,3 \mathrm{~B}$ & $20,1 \mathrm{~B}$ & $20,7 \mathrm{C}$ & $21,5 \mathrm{~B}$ & $22,5 \mathrm{~B}$ \\
\hline \multirow{5}{*}{$\begin{array}{c}\mathrm{Fe} \\
\left(\mathrm{mg} \mathrm{kg}^{-1}\right)\end{array}$} & 1 & $431,6 \mathrm{~A}$ & $565,9 \mathrm{~A}$ & $883,6 \mathrm{~A}$ & $761,4 \mathrm{~A}$ & $1419,7 \mathrm{~A}$ \\
\hline & 2 & $408,3 \mathrm{AB}$ & $441,7 \mathrm{AB}$ & $553,3 \mathrm{~B}$ & 577,9 B & 726,4 B \\
\hline & 3 & $318,2 \mathrm{AB}$ & $410,2 \mathrm{AB}$ & $432,0 \mathrm{~B}$ & $379,5 \mathrm{C}$ & $455,6 \mathrm{C}$ \\
\hline & 4 & $260,4 \mathrm{AB}$ & 380,8 B & 496,4 B & 547,6 BC & $568,3 \mathrm{BC}$ \\
\hline & 5 & $248,7 \mathrm{~B}$ & $336,8 \mathrm{~B}$ & 493,2 B & $548,6 \mathrm{BC}$ & $657,1 \mathrm{~B}$ \\
\hline
\end{tabular}

As médias seguidas de pelo menos uma mesma letra na coluna, para cada corte do capim, não diferem entre si, a $5 \%$ de probabilidade, pelo teste de Tukey. Sendo: T1, T2, T3 e T4, taxas correspondentes a 250; 500; 750 e $1.000 \mathrm{~kg} \mathrm{ha}^{-1} \mathrm{~d}^{-1}$, respectivamente, e T0, tratamento-testemunha, o qual foi irrigado com água da rede de abastecimento. 
De acordo com os dados apresentados na Tabela 3, a produção de MS foi maior no primeiro corte do capim, tal como também observado no trabalho de MATOS et al. (2009). No segundo e terceiro cortes, houve diferença estatística na produção de MS do capim produzido em todas as taxas de aplicação, com exceção daquela relativa ao tratamento T3. A maior produtividade do capim-Tifton 85, quando considerados todos os cortes, foi observada no capim submetido ao tratamento T3, o que, acredita-se, esteja associado ao fornecimento de nutrientes nas quantidades adequadas, sem que se tenha prejuízo ao desenvolvimento das plantas, em razão da maior condição salina ou da concentração de elementos tóxicos no solo.

Observam-se produções mais baixas de MS nos cortes 4 e 5, em todos os tratamentos, o que, suspeita-se, seja decorrente de efeitos climáticos, uma vez que os cortes foram realizados durante o outono. Sendo o capim-Tifton 85 uma planta $\mathrm{C} 4$, a exigência em temperatura e em luminosidade é elevada para a maximização de seu crescimento.

Os valores de produtividade de MS obtidos neste trabalho foram inferiores aos reportados por MATOS et al. (2008b), que ao aplicarem água residuária de laticínios em Sistemas Alagados Construídos (SACs) e cultivados com capim-Tifton 85, verificaram que a produtividade da matéria seca aumentou com o aumento na taxa de carga orgânica aplicada, até a taxa de $469 \mathrm{~kg} \mathrm{ha}^{-1} \mathrm{~d}^{-1} \mathrm{de}$ DBO. No presente trabalho, constatou-se máxima produtividade acumulada de matéria seca (dois cortes) de $15 \mathrm{t} \mathrm{ha}^{-1}$, obtida aos 45 dias de cultivo do capim-Tifton 85. Da mesma forma, foram inferiores aos obtidos por MATOS et al. (2009), que obtiveram produtividade de matéria seca ainda maior, com valor médio, por corte efetuado, de 28,7 $\mathrm{t} \mathrm{ha}^{-1}$, em SACs, no tratamento de águas residuárias da suinocultura (ARS) submetidos a taxas de carregamento de $154,8 \mathrm{~kg} \mathrm{ha}^{-1} \mathrm{~d}^{-1}$ de DBO, e por FIA et al. (2011), que obtiveram produtividades de 5,9 e 6,8 $\mathrm{t} \mathrm{ha}^{-1}$, no primeiro e segundo cortes, respectivamente, aplicando carga de $327 \mathrm{~kg} \mathrm{ha}^{-1} \mathrm{~d}^{-1}$ de DBO da mesma água residuária. Há de se ressaltar, no entanto, que essas comparações devam ser relativizadas, tendo em vista que, nos SACs em referência, havia maior disponibilidade de água e nutrientes para o capim, que no solo utilizado neste experimento.

Observou-se, em todos os tratamentos, a obtenção de maiores teores de proteína bruta (PB) no capim, por ocasião do primeiro corte (Tabela 3). Contudo, os valores registrados nas plantas submetidas aos tratamentos T0 a T4, neste mesmo corte, podem ser considerados elevados. Os menores teores de PB nos cortes 4 e 5 são explicados em razão das maiores idades de corte do capim, 143 e 209 dias, respectivamente. É amplamente reconhecido que o teor de PB de plantas forrageiras declina com o aumento da idade (VASCONCELOS et al., 2009), pois ocorre diminuição na relação lâmina/haste e aumento da lignificação da parede celular da forragem. Outro fator a considerar é que esses últimos cortes foram efetuados durante o período mais frio do ano, período em que a forrageira diminui seu metabolismo, restringindo a absorção de água e nutrientes.

Os teores médios de proteína bruta obtidos no tratamento T0, em todos os cortes, podem ser considerados elevados, uma vez que não ocorreu suprimento de nutrientes via água de abastecimento. Nos tratamentos em que o capim recebeu a aplicação de percolado de RSU, os teores de PB foram crescentes com as taxas aplicadas (ver equação apresentada na Tabela 2). Os teores de PB obtidos neste trabalho podem ser considerados elevados, mesmo quando comparados com aqueles obtidos em outros trabalhos, em que o capim-Tifton 85 também foi cultivado com plena disponibilidade de nitrogênio. QUEIROZ et al. (2004), aplicando ARS em área de cultivo de Tifton 85, obtiveram teor de PB de 19,28 e 19,19 dag kg-1, respectivamente, nos cortes 1 e 2 do capim. MATOS et al. (2008b), aplicando água residuária de laticínios (ARL) em SACs cultivados com capim-Tifton 85 , obtiveram teores de PB de 18,1 a 25,0 dag kg-1. FIA et al. (2011) obtiveram teores médios de PB de 28,4; 27,0; 28,0 e 29,2 dag kg-1 no material coletado em dois cortes de capim-Tifton 85 que recebeu taxas de carregamento de 163,0;327,0; 460,0 e $561 \mathrm{~kg} \mathrm{ha}^{-1} \mathrm{~d}^{-1} \mathrm{de}$ DBO, respectivamente, em SACs utilizados no tratamento de ARS. ERTHAL et al. (2010b) obtiveram teores de PB de 10,45 a 14, 75 dag $\mathrm{kg}^{-1}$ nas folhas de capim-Tifton 85, quando o fertirrigaram com água residuária de bovinocultura (ARB). 
De forma semelhante ao observado para o nitrogênio, registrou-se menor concentração de fósforo nos cortes 4 e 5 (Tabela 3). Acredita-se que as maiores concentrações de fósforo no capim colhido nos três primeiros cortes devam estar associadas ao melhor desenvolvimento das plantas, provavelmente, devido à temperatura e à luminosidade estarem em condições adequadas, já que coincidiram com o período final da primavera (novembro) e início do verão (dezembro e janeiro).

As altas concentrações de fósforo, obtidas no primeiro corte, foram superiores às obtidas, no mesmo capim, por QUEIROZ et al. (2004), MATOS et al. (2008b), ERTHAL et al. (2010b) e FIA et al. (2011). QUEIROZ et al. (2004), ao aplicarem ARS e água da rede de abastecimento em rampas cultivadas com capim-Tifton $85 \mathrm{em}$ sistema de tratamento por escoamento superficial, obtiveram concentrações de fósforo nas folhas de 0,37 e $0,34 \mathrm{dag} \mathrm{kg}^{-1}$, respectivamente. MATOS et al. (2008b), aplicando ARL, em SACs cultivados com capim-Tifton 85, verificaram aumento na concentração de fósforo com o aumento nas taxas de carregamento orgânico superficial (TCOs) aplicadas, o que também foi verificado neste trabalho (ver equações apresentadas na Tabela 2). A menor TCO $\left(66 \mathrm{~kg} \mathrm{ha}^{-1} \mathrm{ano}^{-1}\right)$ proporcionou a concentração de $0,32 \mathrm{dag} \mathrm{kg}{ }^{-1}$, e a maior $\left(570 \mathrm{~kg} \mathrm{ha}^{-1}\right.$ ano ${ }^{-1}$ ), a concentração de 0,41 dag kg ${ }^{-1}$. FIA et al. (2011), ao tratarem ARS em SACs cultivados com capim-Tifton 85, com taxas de carregamento entre 163 e $561 \mathrm{~kg} \mathrm{ha}^{-1} \mathrm{~d}^{-1}$ de $\mathrm{DBO}_{5}$, obtiveram concentrações médias variando de 0,79 a $0,97 \mathrm{dag}_{\mathrm{kg}^{-1}}$,em dois cortes realizados nas plantas. ERTHAL et al. (2010b) obtiveram concentrações variando de 0,17 a $0,19 \mathrm{dag} \mathrm{kg}^{-1}$ de $\mathrm{P}$, quando fertirrigaram o capim-Tifton com ARB, em diferentes taxas de aplicação. Uma comparação entre os dados apresentados na literatura e os obtidos neste trabalho fica prejudicada, principalmente quando a comparação é feita com cultivo em SACs. Assim, a comparação mais adequada seria com os valores apresentados por QUEIROZ et al. (2004), tendo em vista que a aplicação também foi feita no solo. Nesse caso, verifica-se que a concentração de $\mathrm{P}$ no tecido vegetal da parte aérea do capimTifton 85 , obtido no primeiro corte, neste trabalho, foi sempre superior e, nos demais cortes, no mínimo igual ao valor médio de $0,37 \mathrm{dag} \mathrm{kg}^{-1}$ obtido por QUEIROZ et al. (2004) com a aplicação de ARS, indicando que o percolado supriu o capim com $\mathrm{P}$, de forma semelhante ou superior ao que proporcionou a ARS.

As concentrações médias de potássio na parte aérea do capim-Tifton 85 , no primeiro corte, foram maiores que as obtidas nos demais cortes, nas plantas submetidas a todos os tratamentos, à exceção das submetidas ao tratamento T3, no qual a média foi estatisticamente igual à dos cortes $3 \mathrm{e}$ 4. A concentração de $\mathrm{K}$ no capim-Tifton 85 , ao contrário do observado em relação a $\mathrm{N}$ e $\mathrm{P}$, manteve-se relativamente constante durante o período de crescimento da planta. As concentrações de $\mathrm{K}$ obtidas no primeiro corte foram superiores às obtidas por MATOS et al. (2008b) que, ao tratarem ARL em SACs cultivados com capim-Tifton 85, obtiveram concentrações de potássio na faixa de 1,30 a $1,52 \mathrm{dag} \mathrm{kg}^{-1}$ e por FIA et al. (2011), que obtiveram concentrações de 2,11; 1,93; 2,10 e 2,04 dag kg ${ }^{-1}$, nas folhas do mesmo capim, quando receberam taxas de carregamento de 163; 327; 460 e $561 \mathrm{~kg} \mathrm{ha}^{-1} \mathrm{~d}^{-1}$ de $\mathrm{DBO}_{5}$, respectivamente, em SACs utilizados no tratamento de ARS.

As altas concentrações de $\mathrm{K}$ no percolado de RSU, de 106,3 a $3.663,5 \mathrm{mg} \mathrm{L}^{-1}$ (Tabela 1) superam os valores citados por FIA et al. (2011) em ARS $\left(103 \pm 70 \mathrm{mg} \mathrm{L}^{-1}\right)$. Ainda assim, foram obtidas concentrações semelhantes de $\mathrm{K}$ na parte aérea do capim-Tifton 85 , à exceção do que foi obtido no T4 (taxa de aplicação de $1.000 \mathrm{~kg} \mathrm{ha}^{-1} \mathrm{~d}^{-1} \mathrm{de} \mathrm{DBO}$ ), que foi de $3,66 \mathrm{dag} \mathrm{kg}^{-1}$. O fato de ter sido cultivado em ambiente de SACs é fator muito importante na obtenção desses resultados, já que, como comentado anteriormente, a disponibilidade de água e nutrientes é muito maior nesse meio.

As plantas que receberam o percolado de RSU apresentaram concentrações de potássio nas folhas que foram superiores às obtidas naquelas que receberam água da rede de abastecimento. GOMIDE (1994) considerou a concentração de potássio na faixa de 1,5 a 2,0 dag kg ${ }^{-1}$ como normal em plantas forrageiras, com adequado suprimento de potássio, via adubação mineral. As concentrações de $\mathrm{K}$ na parte aérea das plantas submetidas aos tratamentos T1 e T2, em todo o período de cultivo, estão dentro da faixa considerada normal pelo autor supracitado, enquanto as concentrações de potássio, na parte aérea das plantas submetidas aos tratamentos T3 e T4, 
encontram-se acima desta faixa, indicando absorção de "luxo" deste elemento químico pelo capim-Tifton 85, tal como também verificado por ERTHAL et al. (2010b).

As concentrações de cálcio na parte aérea do capim-Tifton foram maiores, por ocasião do primeiro corte, em todos os tratamentos, à exceção do T0, no qual o valor não diferiu do encontrado no terceiro corte (Tabela 3). Os valores médios, encontrados nos tratamentos T1, T2, T3 e T4, podem ser considerados normais para capim-colonião (o de faixa de concentração mais alta entre os citados), segundo MARTINEZ et al. (1999), que é de 0,40 a 1,02 dag $\mathrm{kg}^{-1}$.

Plantas que receberam o percolado de RSU apresentaram concentrações de cálcio superiores às obtidas por aquelas que receberam água da rede de abastecimento, conforme pode ser verificado, analisando-se as equações apresentadas na Tabela 2, indicando que o percolado de RSU disponibilizou maior quantidade deste nutriente para elas. De maneira semelhante, QUEIROZ et al. (2004), aplicando ARS em capim-Tifton 85, observaram que todas as forrageiras em avaliação apresentaram concentrações de cálcio nas folhas $\left(0,56 \mathrm{dag} \mathrm{kg}^{-1}\right)$, significativamente superiores àquelas obtidas em plantas submetidas à aplicação da água da rede de abastecimento $(0,41$ dag $\mathrm{kg}^{-1}$ ), em dois cortes da planta. ERTHAL et al. (2010b) também observaram que, à exceção da maior dose de ARB, o capim-Tifton 85 apresentou concentrações significativamente maiores de cálcio nas folhas $\left(0,45\right.$ a $\left.0,57 \mathrm{dag} \mathrm{kg}^{-1}\right)$ que a testemunha $\left(0,38 \mathrm{dag} \mathrm{kg}^{-1}\right)$, que não recebeu água residuária. Os resultados obtidos por esses autores foram bastante próximos aos obtidos no presente trabalho.

De acordo com os dados apresentados na Tabela 3, observa-se que as maiores concentrações de magnésio nas folhas foram obtidas por ocasião do primeiro corte do capim, tendo sido obtidos valores entre 0,29 e $0,32 \mathrm{dag} \mathrm{kg}^{-1}$, superiores aos obtidos por QUEIROZ et al. (2004), que encontraram concentração média de 0,18 dag kg$^{-1}$ de magnésio nas folhas do mesmo capim, quando aplicaram ARS em rampas de tratamento por escoamento superficial; e por ERTHAL et al. (2010b), que encontraram valores entre 0,15 e $0,19 \mathrm{dag}_{\mathrm{kg}^{-1}}$, no terceiro corte do capim. Verificou-se a tendência de a concentração de magnésio diminuir na parte aérea do capim-Tifton 85, com o número de cortes ou a idade da planta.

Observa-se, com base nos dados apresentados na Tabela 3, que o capim-Tifton 85 apresentou maior concentração de potássio que cálcio e magnésio, em vista de sua grande disponibilidade no percolado de RSU (Tabela 1). De maneira semelhante, LO MONACO et al. (2007) chegaram a constatar sintoma de deficiência de cálcio e magnésio na folha do cafeeiro, em razão do excesso de potássio no solo, quando o fertirrigaram com água residuária de seu processamento.

Embora tenham sido aplicadas grandes quantidades de sódio, as plantas apresentaram concentrações deste elemento na faixa considerada normal $\left(0,04\right.$ a $0,18 \mathrm{dag} \mathrm{kg}^{-1}$, à exceção do corte 1 nas plantas receptoras da maior taxa de aplicação, que foi de $0,25 \mathrm{dag} \mathrm{kg}^{-1}$ ) (Tabela 3 ). Os valores obtidos neste trabalho $\left(0,12\right.$ a $\left.0,25 \mathrm{dag} \mathrm{kg}^{-1}\right)$, no primeiro corte, foram, porém, superiores aos obtidos por MATOS et al. (2008b), que encontraram concentrações de sódio na faixa de 0,045 a $0,07 \mathrm{dag} \mathrm{kg}^{-1}$ e por FIA et al. (2011), que encontraram concentrações foliares na faixa de 0,02 a 0,03 dag $\mathrm{kg}^{-1}$ quando cultivaram a mesma espécie vegetal, em SACs, no tratamento de águas residuárias de laticínios e de suinocultura, respectivamente. Da mesma forma, foram superiores aos obtidos por QUEIROZ et al. (2004) que, ao aplicarem água residuária da suinocultura (ARS) em capim-Tifton 85 , verificaram concentrações médias de $\mathrm{Na}$ de $0,04 \mathrm{dag} \mathrm{kg}^{-1}$, e por ERTHAL et al. (2010b), que encontraram valores variando de 0,03 a $0,04 \mathrm{dag} \mathrm{kg}^{-1}$ no primeiro, segundo e terceiro cortes em folhas de capim-Tifton 85, quando o fertirrigaram com água residuária de bovinocultura. MATOS et al. (2011) observaram, no entanto, que o capim-Tifton 85 foi pouco eficiente na remoção deste cátion, quando sua capacidade extratora foi comparada à de outras forrageiras, no tratamento de esgoto doméstico em sistemas alagados construídos.

Comparando-se as concentrações de micronutrientes no capim-Tifton 85 com a ideal nas folhas de diferentes capins (MARTINEZ et al.,1999), verificou-se que a concentração de Mn nas folhas do Tifton 85 , obtidas em todos os tratamentos neste trabalho, superou às estabelecidas para 0 
capim- -colonião (faixa de 80 - $100 \mathrm{mg} \mathrm{kg}^{-1}$ ), porém ficaram abaixo das estabelecidas para o capimjaraguá (faixa de $200-300 \mathrm{mg} \mathrm{kg}^{-1}$ ) e capim-elefante (faixa de $150-200 \mathrm{mg} \mathrm{kg}^{-1}$ ).

Observa-se que, na menor taxa de aplicação de percolado (T1), as concentrações de Cd nas folhas do capim não diferiram entre os cortes efetuados nas plantas. No entanto, nos tratamentos T2, T3 e T4, observou-se maior concentração deste elemento nas folhas, no primeiro corte das plantas do que nos seus cortes $3 ; 4$ e 5 .

As concentrações de $\mathrm{Pb}$ nas folhas, obtidas no primeiro e segundo cortes do capim, foram maiores que as obtidas nos demais cortes, em todos os tratamentos avaliados, à exceção do tratamento T2 (250 $\mathrm{kg} \mathrm{ha}^{-1} \mathrm{~d}^{-1}$ de DBO).

Nos tratamentos 2; 3 e 4, observa-se maior conteúdo de ferro nas folhas das plantas no corte 1 , enquanto na ausência de percolado e na taxa de aplicação relativa ao tratamento 1 ocorreu maior concentração deste elemento nas folhas das plantas coletadas no corte 1, quando comparado ao que foi obtido no corte 5. QUEIROZ et al. (2004), aplicando água residuária da suinocultura em capimTifton 85 , verificaram concentração média de ferro de $400 \mathrm{mg} \mathrm{kg}^{-1}$, valor este próximo ao encontrado no presente trabalho, nas plantas submetidas ao tratamento T2 $\left(250 \mathrm{~kg} \mathrm{ha}^{-1} \mathrm{dia}^{-1} \mathrm{de}\right.$ DBO), mas inferior aos valores obtidos nos tratamentos em que foram aplicadas taxas mais altas de percolado de RSU.

Segundo MARTINEZ et al. (1999), a concentração de ferro considerada ideal para o capim-colonião é de 100 - $150 \mathrm{mg} \mathrm{kg}$, para o capim-jaraguá é de $150-200 \mathrm{mg} \mathrm{kg}^{-1}$ e para o capimelefante é de 150 - $200 \mathrm{mg} \mathrm{kg}^{-1}$. Independentemente do corte e da quantidade de percolado aplicado, as concentrações de ferro registradas são superiores a esses valores.

As concentrações de cobre, zinco e níquel no capim-Tifton 85 encontraram-se abaixo do limite de detecção do aparelho, indicando que a adição do percolado de RSU não proporcionou considerável aumento nas concentrações disponíveis destes metais pesados.

\section{CONCLUSÕES}

Houve aumento na produtividade de matéria seca, nos teores de proteína bruta e tendência de aumento nas concentrações de $\mathrm{N}, \mathrm{K}, \mathrm{Na}, \mathrm{Ca}, \mathrm{Mg}, \mathrm{Mn}, \mathrm{Cd}, \mathrm{Pb}$ e Fe na parte aérea do capim com as taxas de aplicação do percolado RSU.

Em todos os cortes, ocorreu efeito positivo das taxas de aplicação do percolado RSU na PB, enquanto, para a produtividade de MS, tal efeito ocorreu apenas nos cortes 3, 4 e 5 do capim.

Em relação ao efeito dos cortes na concentração de nutrientes e poluentes nas folhas do capim, para N, P e Mn, a tendência foi decréscimo na concentração com o número de cortes; para $\mathrm{Cd}, \mathrm{Pb}$ e Fe, estabilização após o $2^{\circ}$ ou $3^{\circ}$ cortes; e para $\mathrm{Na}$, aumento na concentração após $3^{\circ}$ corte. No que se refere a $\mathrm{K}$, Ca e $\mathrm{Mg}$, houve instabilidade nos valores.

A concentração de micronutrientes nas folhas do capim-Tifton 85 situou-se na faixa considerada normal para capins, enquanto a de metais pesados foi considerada negligenciável.

\section{REFERÊNCIAS}

ALLEN, R. G.; PEREIRA, L. S.; RAES, D.; SMITH. M. Crop evapotranspiration - Guidelines for computing crop water requirements. In: FAO. Irrigation and Drainage. Rome, 1998. 308 p. (Paper, 56)

APHA - AMERICAN PUBLIC HEALTH ASSOCIATION; AWWA - AMERICAN WATER WORKS ASSOCIATION; WEF - WATER ENVIRONMENT FEDERATION. Standard methods for the examination of water and wastewater. 21.ed. Washington: APHA/AWWA/WEF, 2005. 1268p. 
DRUMOND, L. C. D.; ZANINI, J. R.; AGUIAR, A. P. A.; RODRIGUES, G. P.; FERNANDES, A. L. T. Produção de matéria seca em pastagem de Tifton 85 irrigada, com diferentes doses de dejeto líquido de suíno. Engenharia Agrícola, Jaboticabal, v.26, n.2, p.426- 433, maio/ago. 2006.

ERTHAL, V. J. T.; FERREIRA, P. A. F.; MATOS, A. T.; PEREIRA, O. G. Alterações físicas e químicas de um Argissolo pela aplicação de água residuária de bovinocultura. Revista Brasileira de Engenharia Agrícola e Ambiental, Campina Grande, v.14, n.5, p.467-477, 2010a.

ERTHAL, V. J. T.; FERREIRA, P. A. F.; PEREIRA, O. G; MATOS, A. T. Características fisiológicas, nutricionais e rendimento de forrageiras fertirrigadas com água residuária de bovinocultura. Revista Brasileira de Engenharia Agrícola e Ambiental, Campina Grande, v.14, n.5, p.458-466, $2010 \mathrm{~b}$.

FIA, F. R. L.; MATOS, A. T.; FIA, R.; LAMBERT, T. F.; MATOS, M. P. Remoção de nutrientes por Typha latifolia e Cynodon spp cultivadas em sistemas alagados construídos. Revista Ambiente e Água, Taubaté, v.6, n.1, p.77-89, 2011.

GOMIDE, J. A. Fisiologia do crescimento livre de plantas forrageiras. In: PEIXOTO, A. M.; MOURA, J. C.; FARIA, V. P. (Ed.) Pastagens: fundamentos da exploração racional. 2. ed Piracicaba: Fundação de Estudos Agrários Luiz de Queiroz, 1994. p. 1-14.

GUTIERREZ, K. G.; MATOS, A. T.; ROSSMANN, M. Influência da presença de camada de resíduos de construção civil na remoção de metais pesados em percolado recirculado de aterro sanitário. Revista Ambiente e Água, Taubaté, v.5, n.2, p.87-98, 2010.

LO MONACO, P. A. V.; MATOS, A. T.; MARTINEZ, H. E. P.; FERREIRA, P. A.; RAMOS, M. M. Avaliação do estado nutricional do cafeeiro após fertirrigação com águas residuárias da lavagem e descascamento de seus frutos. Engenharia na Agricultura, Viçosa-MG, v.15, n.4, p.392-399, out./nov., 2007.

MANTOVANI, E. C.; BERNARDO, S.; PALARETTI, L. F. Irrigação - princípios e métodos. 3.ed. Viçosa: Editora UFV, 2009. 355 p.

MARTINEZ, H. E. P.; CARVALHO, J. G.; SOUZA, R. B. Diagnose Foliar. In: RIBEIRO, A.C.; GUIMARÃES, P. T. G.; ALVAREZ, V. V. H. (Ed.). Recomendações para o uso de corretivos e fertilizantes em Minas Gerais, $5^{a}$ Aproximação. Viçosa - MG: Comissão de Fertilidade do Solo do Estado de Minas Gerais, 1999. p.143-168.

MATOS, A. T.; ABRAHÃO, S.S.; LO MONACO, P. A. V.; SARMENTO, A.P.; MATOS, M. P. Capacidade extratora de plantas em sistemas alagados utilizados no tratamento de águas residuárias de laticínios. Revista Brasileira de Engenharia Agrícola e Ambiental, Campina Grande, v.14, n.12, p.1.311-1.317, 2010a.

MATOS, A. T.; ABRAHÃO, S.S.; PEREIRA, O. G. Desempenho agronômico de capim-Tifton 85 (cynodon spp) cultivado em sistemas alagados construídos utilizados no tratamento de água residuária de laticínios. Revista Ambiente e Água, Taubaté, v.3, n.1, p.43-53, 2008b.

MATOS, A. T.; CARVALHO, A. L.; AZEVEDO, I. C. D. A. Viabilidade do aproveitamento agrícola de percolados de resíduos sólidos urbanos. Revista Brasileira de Engenharia Agrícola e Ambiental, Campina Grande, v.12, n.4, p.435-440, 2008a.

MATOS, A. T.; FREITAS, W. S.; BRASIL, M. S.; BORGES, A. C. Influência da espécie vegetal cultivada nas condições redox de sistemas alagados construídos. Engenharia Agrícola, Jaboticabal, v.30, n.3, p.518-526, maio/jun. 2010b.

MATOS, A. T.; FREITAS, W. S.; LO MONACO, P. A. V. Capacidade extratora de diferentes espécies vegetais cultivadas em sistemas alagados utilizados no tratamento de águas residuárias da suinocultura. Revista Ambiente e Água, Taubaté, v.4, n.2, p.31-45, 2009. 
MATOS, A. T.; LO MONACO, P. A. V.; FOLLI, C. P. D.; PELLINI, S.; ARANTES, S. B. Concentração de macronutrientes e de sódio na parte aérea de espécies vegetais, cultivadas de forma consorciada e em diferentes posições em sistemas alagados construídos. Engenharia na Agricultura, Viçosa-MG, v.19, n.2, p.141-151, mar. /abr. 2011.

QUEIROZ, F. M.; MATOS, A. T.; PEREIRA, O. G.; OLIVEIRA, R. A.; LEMOS, F. A. Características químicas do solo e absorção de nutrientes por gramíneas em rampas de tratamento de águas residuárias da suinocultura. Engenharia na Agricultura. Viçosa-MG, v.12, n.2, p.77-90, abr./jun. 2004.

SILVA, D. F.; MATOS, A. T.; PEREIRA, O. G.; CECON, P. R.; BATISTA, R. O.; MOREIRA, D. A. Alteração química de solo cultivado com capim-Tifton 85 (Cynodon spp.) e fertirrigado com percolado de resíduo sólido urbano.Acta Scientiarum. Technology, Maringá, v.33, n.3, p.243-251, 2011.

SILVA, D. F.; MATOS, A. T.; PEREIRA, O. G.; CECON, P. R.; MOREIRA, D. A. Disponibilidade de sódio em solo com capim-Tifton e aplicação de percolado de resíduo sólido. Revista Brasileira de Engenharia Agrícola e Ambiental, Campina Grande, v.14, n.10, p.1.0941.100, 2010.

SILVA, D.J.; QUEIROZ, A.C. de. Análise de alimentos: métodos químicos e biológicos. 3.ed. Viçosa - MG: UFV, 2002. 235 p.

SLACK, R.J.; GRONOW, J.R.; VOULVOULIS, N. Household hazardous waste in municipal landfills: contaminants in leachate. Science of the Total Environment, Amsterdam, v.337, p.119$137,2005$.

VASCONCELOS, W. A.; SANTOS, E. M.; ZANINE, A. M.; PINTO, T. F.; LIMA, W. C.; EDVAN, R. L.; PEREIRA, O. G. Valor nutritivo de silagens de capim-mombaça (Panicum maximum Jacq.) colhido em função de idades de rebrotação. Revista Brasileira de Saúde e Produção Animal, Salvador, v.10, n.4, p.874-884 out./dez. 2009. 